\title{
Cervical Cytology Screening at BPKIHS, Dharan
}

\author{
Hanoon P. Pokharel, Uma Singh, Aravind Sinha \\ Department of Gynecology \& Obstetrics and 'Pathology, \\ BP Koirala Institute of Health Sciences, Dharan, Nepal
}

\begin{abstract}
Aim: To find out the burden of carcinoma cervix $(\mathrm{Ca} C \mathrm{Cx})$ and the precancerous lesions among women attending general Gynecological OPD of Dept of Obstetrics and Gynecology, BPKIHS; and to evaluate the opportunity cost and its impact in treatment.

Methods: This is a retrospective analysis of data collected from the OPD Register of the Department of Obstetrics / Gynecology and Pathology BPKIHS during the five years period 2001- 2005 of the women who came with abnormal vaginal bleeding and were screened for cervical pathology after two weeks course of antibiotics followed by Pap smear.

Results: 3748 Pap smear was taken during the period of 2000-2005 in the women (age $21-68$ years) attending 21 Gynecological OPD and reviewed in the Cytology Laboratory of Dept of Pathology in BPKIHS. The smears were normal (731) inflammatory smear (2896) squamous cell abnormality $(81=2.16 \%)$ and squamous cell and carcinoma $(40=1.06 \%)$.

Conclusion: Cervical cytology screening is the best Cancer-Screening tool ever developed in decades which is highly applicable in all the countries and has beneficial effect of detecting pre invasive cervical cancer as well as carcinoma in stage I disease.
\end{abstract}

Key words: Cervical cytology screening, squamous cell abnormality, squamous cell and carcinoma

\section{Introduction}

In Nepal still there is no universal screening programme. The women who attend Gynaecology OPD with complaints of Vaginal discharge or who have unhealthy looking cervix are only screened routinely after a course of antibiotic or local vaginal antibiotic ${ }^{(1)}$. There are no organized or high level opportunistic screening programmes for cervical cancer in the country. The rates are high particularly in the rural areas and the absolute number of cases is on the rise due to population growth. HPV testing is 2.3times as expensive as a single pap test, but cheaper than a colposcoppy ${ }^{2}$.

Unfortunately, most cases present in a late stage, when treatment is more costly, complicated, and much less likely to be successful. Surgery and radiotherapy, which are the only available treatments for cancer cervix, are not accessible to all victims in the developing countries and when available, women suffer from severe morbidities with overall survival rate of $40 \%$. Hence; prevention is the most primary approach to control the disease. The lower incidence in developed country is mainly attributed to the cancer screening programme and treatment of precancerous lesions. In UK, after major changes in the cervical screening programme in 1990 , mortality had fallen to 3.7 per 100,000 by $1997^{3}$.

Cervical cancer is the third most common cancer in the world and the second most common cancer ( $12 \%$ of all cancer cases) and leading cause of the death from cancer in women in developing countries ${ }^{4}$. In most of the developing countries including Nepal, it is the most common cancer in female. In Nepal, a country of approximately 25 million people, cervical cancer is slightly more common than breast cancer, and accounts for almost one third of all cancer in females, with more than 2100 new cases being detected each year (an incidence rate of over 18 per 100,000 per annum). There are many screening tests to detect cervical cancer like VIA (Visual inspection with acetic acid), HPV testing and Colposcopy.

The purpose of this article is to find out the burden of $\mathrm{Ca} \mathrm{Cx}$ and the precancerous lesions among women attending general gynecological OPD of dept

Corresspondence

Hanoon P. Pokharel. MD

Assoc Prof Dept of Gyn/obs, BPKIHS, Dharan

email: hanoonparas@gmail.com 
of Obstetrics and Gynecology, BPKIHS; and to evaluate the opportunity cost and its impact in treatment.

\section{Methods}

Study Design: This is a retrospective analysis of data, which were collected from the Register in the Department of Obstetrics / Gynecology and Pathology in the period of 2001-2005.

All patients attending the Gynecological OPD in the Department of Obstetrics \& Gynecology of BPKIHS with the presenting complaints of pelvic Inflammatory disease and abnormal vaginal bleeding were screened for any cervical pathology. These patients after thorough physical examination (Including per speculum and per vaginal examination) were given 2 weeks course of antibiotics and asked to come for Pap smear screening tests. Most of them did not agree to take antibiotic course as they were coming from far region, so Pap smear was performed in the same sitting.

After following all pre requisite of a Pap smear screening, with wooden spatula the exocervix and the endocervix is scrapped and the specimen fixed in $96 \%$ ethynyl alcohol \& immediately asked the patient to submit in Pathology lab. The patients were asked to follow with the reports and accordingly the treatment was advised. If during per speculum and per vaginal examination if any growth was visible cervical punch biopsy was indicated at the same sitting \& the specimen sent to the Pathology department. All the five year records were reviewed from the registry.

Pap smear were taken during the period of 2000-2005 in the Gynecological OPD was sent to Cytology Laboratory of Dept of Pathology for reporting. These reports were entered in Excel database. Analyses were done with update of review of published literature from the region

\section{Results}

The total number of 3748 women who underwent cervical cytology was analysed. Screening gradually increased from 2001 to 2005. (Table I) The women attending general gynecology OPD with variable presentation and who underwent screening ranged from 21 to 68 years.

Table 1. Outcome of cervical screening from 2001-2005

\begin{tabular}{llllll}
\hline year & normal & $\begin{array}{l}\text { inflammatory } \\
\text { smear }\end{array}$ & $\begin{array}{l}\text { squamous cell } \\
\text { abnormality }\end{array}$ & $\begin{array}{l}\text { squamous cell } \\
\text { carcinoma }\end{array}$ & Totalwomens \\
\hline 2001 & 82 & 439 & 22 & 2 & 545 \\
2002 & 154 & 475 & 18 & 12 & 659 \\
2003 & 156 & 625 & 9 & 7 & 797 \\
2004 & 164 & 656 & 18 & 10 & 848 \\
2005 & 175 & 701 & 14 & 9 & 899 \\
\hline Total & 731 & 2896 & 81 & 40 & 3748 \\
\hline
\end{tabular}

Table 2. The results of inflammatory smear

\begin{tabular}{lllllll}
\hline & BV & Tricho & Monilial & HPV & H.S. & Total \\
\hline 2001 & 201 & 100 & 133 & 3 & 2 & 439 \\
2002 & 222 & 163 & 80 & 5 & 5 & 475 \\
2003 & 300 & 115 & 195 & 10 & 5 & 625 \\
2004 & 335 & 226 & 73 & 9 & 3 & 646 \\
2005 & 325 & 265 & 88 & 15 & 8 & 701 \\
\hline Total & 1383 & 869 & 569 & 42 & 23 & 2886 \\
\hline
\end{tabular}

Table 3. Distribution of Cervical Intraepithelial Neoplasia.

\begin{tabular}{lllll}
\hline & CIN-1 & CIN-2 & CIN-3 & (Total) \\
\hline 2001 & 12 & 7 & 3 & 22 \\
2002 & 8 & 8 & 2 & 18 \\
2003 & 5 & 3 & 1 & 9 \\
2004 & 13 & 4 & 1 & 18 \\
2005 & 9 & 3 & 2 & 14 \\
\hline Total & 47 & 25 & 9 & 81 \\
\hline
\end{tabular}


Table 4. Outcome of squamous cell carcinoma

\begin{tabular}{llllll}
\hline & Stage I & II & III & IV & Total \\
\hline 2001 & - & - & 2 & - & 2 \\
2002 & 4 & 3 & 3 & 2 & 12 \\
2003 & - & - & 6 & 1 & 7 \\
2004 & 3 & 1 & 4 & 2 & 10 \\
2005 & 2 & 2 & 5 & - & 9 \\
\hline Total & 9 & 6 & 20 & 5 & 40 \\
\hline
\end{tabular}

Majority of patients revealed inflammatory smears. The most common infections being Bacterial vaginosis (Gardenella vaginalis), Trichomonas vaginallis and Moniaial infections. There were HPV and herpes simplex virus too (Table 2).

The total number over 5year with invasive carcinoma was seen to be 40 . From the table we can see that the patient presented with stage III Ca Cx was $50 \%$ of the total number of invasive Carcinoma. Unfortunately, the treatment is more costly, complicated and much less likely to be successful. If we could implement effective screening the cost of treatment will reduce dramatically. (Table 3)

Out of 81 patients among squamous cell abnormalities over 5years at BPKIHS 47 patients presented with CIN I (47/81); 25 patients with CIN II (25/81) and 9 patients (9/81) with CIN III (table 3 ). The distribution of patients with invasive carcinoma is shown in (Table 4).

\section{Discussion}

Carcinoma cervix is the most common genital cancer in developing countries, which is almost always preceded by cervical intraepithelial neoplasia with a long latent phase of 10-15 years which facilitates effective screening. The objective of cervical screening program is to prevent invasive cancer of cervix by detecting and treating pre-invasive disease of cervix. Successful screening of the entire population and appropriate treatment of the lesions could reduce the risk of developing cervical cancer to one tenth of the risk of unscreened population. Papanicolaou and Trant first reported the use of exfoliate cervical cytology for the diagnosis of cervical cancer and precancerous lesion. The Pap smear can often, but not always show the presence or absence of abnormal cells consistent with the histological diagnosis of dysplasia or cancer ${ }^{5}$. Inadequate sampling of the transformation zone, poor collection and fixation failure of specimen, inclusion of excessive blood, inflammatory or necrotic material, failure of the precancerous lesions to shed cells in sufficient quantities for cytological detection and limited ability to sample endocervical canal, result in high number of false negative results. Sampling involves collecting exfoliated cells from the ectocervix and endocervical canal and transferring them to a glass microscope slide or into a liquid transport medium for review. Patient preparation and proper provider technique can help optimize the collection of cells. In developing countries with low resource setting where cytological screening is not easily available, a resurgence of interest has occurred in the use of noncytological methods. Combined with other methods of screening, Visual screening might reduce the error rates ${ }^{2}$.

\section{Conclusion}

In our setup any women attending general OPD with different complaints should be encouraged to get a pap smear done. At least this will fulfill a single life time screening. If she is unable to afford then direct visual inspection with speculum should be made mandatory. Cervical cytology screening is the best CancerScreening tool ever developed. In all countries where it has been widely used, the incidence of cervical cancer has been decreased by about $70 \%$. In the past two decades there has been great progress in our understanding of the natural history of cervical neoplasia. There are many scientific evidences to implement selective cervical cancer screening, which has been proved to be most cost effective and successful health programme.

\section{References}

1. Pradhan N, Giri K, Rana A. Cervical cytological study in unhealthy \& healthy looking cervix. Nepal Journal of Obs. Gyn 2007; 2 (1): 42-47.

2. ACOG Practice Bulletin Cervical Cytology screening. Int J. of Gyn.Obs.(2003),237-247.

3. Quinn $\mathrm{M}$ et al. Effect of screening on incidence and mortality from cancer of cervix in England, evaluation based on routinely collected statistics. BMJ 1999; 218: 904-8.

4. Pisani P, Parkin DM, Bray F, Ferlay J. Estimates of the world wide mortality from 25 cancers in 1990.Int J cancer 1999:83;18-29.

5. Cervical cytology screening ACOG Technology Assessment.American college of Obstetrician \& Gynaecologists. Obstet Gynecol 2002:100: 1423-7. 